\title{
The current status of ultrasound practice in Kano metropolis, Nigeria
}

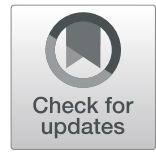

\author{
Mohammed Sidi ${ }^{1}$, Ghali Makoda Sani ${ }^{2}$, Anas Ya'u ${ }^{1 *}$, Joseph Dlama Zira ${ }^{3}$, Shem Samuel Loshugno ${ }^{4}$ and \\ Geofrey Luntsi ${ }^{5}$
}

\begin{abstract}
Background: Ultrasound has been in clinical use to image the human body for over half a century. An audit should be performed on professional practice aimed at taking corrective measures where errors are identified and improvement in the practice when errors are not detected. This study is aimed at evaluating the current status of ultrasound practice in Kano metropolis, Nigeria.

Results: Out of the 70 (100\%) administered questionnaires, 68 (97.14\%) were returned, and 64 (91.43\%) were properly filled. Fifty-eight (90.6\%) knew the exact meaning of ultrasound, and 34 (53\%) considered ultrasound as a modality of choice for imaging and diagnosis of abdominal masses. None of the participants was exposed to advanced ultrasound technology. Only $3(4.7 \%)$ and 5 (7.8\%) of the respondents performed infection control, air reverberation pattern and electronic noise checks.

Conclusion: Ultrasound practitioners demonstrate good knowledge of ultrasound and its application. However, there was unavailability of advanced ultrasound equipment. There was also poor understanding and practice of quality assurance among practitioners. Ultrasound equipment might have been grossly underutilized and qualities of images produced by the equipment are not certain were optimal.
\end{abstract}

Keywords: Status, Ultrasound, Practice, Audit

\section{Background}

Ultrasound has been in clinical use to image the human body for over half a century $[1,2]$. It is a portable, safe, effective, accessible and real-time imaging modality that is capable of providing clinically relevant information about most parts of the human body in a rapid and costeffective fashion [1-3]. Ultrasound imaging investigations can assist in the diagnosis and monitoring of disease conditions [4]. In many cardiovascular diseases, it has replaced invasive methods as the primary means of evaluation [3]. Furthermore, it is the most applicable imaging technique for guiding biopsies and fine needle aspirations that are performed percutaneously provided the lesion can be visualized sonographically [5].

\footnotetext{
* Correspondence: ayau.radg@buk.edu.ng

${ }^{1}$ Department of Medical Radiography, Faculty of Allied Health Sciences,

Bayero University, Kano, Nigeria

Full list of author information is available at the end of the article
}

Ultrasound practitioners come from a wide range of professional backgrounds which include radiologists, radiographers, sonographers, nurses, midwives, physiotherapists, obstetricians and clinical scientists $[4,6,7]$. Sonography is a profession to some practitioners while to others is a diagnostic or therapeutic tool used to support their main professional role [8]. It is a primary imaging modality in the daily work of sonographers and sonologists [8]. Ultrasonography requires a practice of hand-eye coordination skills and the use of intelligence, medical knowledge and experience [9]. Training for diagnostic ultrasound examinations and procedures is varied; the level, duration and intensity depend on the desired use [4]. Medical doctors undergoes radiology residency programme that lasts for an average duration of 5 years in African countries before being certified to practise radiological procedures including ultrasonography $[10,11]$. Residency is defined as the constellation

\section{Springer Open}

(c) The Author(s). 2021 Open Access This article is licensed under a Creative Commons Attribution 4.0 International License, which permits use, sharing, adaptation, distribution and reproduction in any medium or format, as long as you give appropriate credit to the original author(s) and the source, provide a link to the Creative Commons licence, and indicate if changes were made. The images or other third party material in this article are included in the article's Creative Commons licence, unless indicated otherwise in a credit line to the material. If material is not included in the article's Creative Commons licence and your intended use is not permitted by statutory regulation or exceeds the permitted use, you will need to obtain permission directly from the copyright holder. To view a copy of this licence, visit http://creativecommons.org/licenses/by/4.0/. 
of learning activities carried out to enable doctors to develop relevant competencies and deeper knowledge in specific subject areas after completion of basic medical education [11]. In Nigeria, radiographers shall additionally possess a postgraduate diploma in Ultrasonography of the Nigerian Institute of Radiography or any other qualifications recognized by the Board before being certified to practise general ultrasonography; otherwise, they are restricted to obstetric and gynaecology scan [12]. The largest group of professionals working in ultrasound has come from a radiography background via accredited programmes of education, delivered by higher education establishments and accredited by the Consortium for the Accreditation of Sonographic Education (CASE) in the UK [8]. Some medical specialities perform specialized ultrasound scans as part of their training, like gynaecologists and cardiologists [4]. A high level of diagnostic accuracy of sonographers/radiographers has been shown in a number of studies across all subspecialties [7, 13-15]. The imaging modality is an operator dependent, and the usefulness of an ultrasound examination depends on the experience and the capability of the ultrasound examiner [4]. In the hands of an untrained or poorly trained person, ultrasound may be misleading and even dangerous because misinterpretation will lead to an erroneous diagnosis [4].

Ultrasound is among the most rapidly advancing imaging techniques; advances in equipment technology allow users to discover a wide range of pathologic conditions with minimal image noise and improve resolution [16]. Functional methods such as elastography have been clinically introduced, and tissue characterization is improved by contrast-enhanced scans [16]. The recent advances that have produced the most significant impact on the general public and ultrasound community have been the ability to view three-dimensional (3D) images in real time [17]. Doppler ultrasound is also an added advantage that provides vital information on the haemodynamics of the cardiovascular system [17].

Quality assurance (QA) of ultrasound systems is necessary to ensure the reliability of results and to check for deterioration in performance [18]. It is a highly recommended procedure intended to test the performance of clinical instrumentation and monitor its deterioration periodically over time, which may be responsible for a slight but progressive degradation of image quality [19]. Equipment performance testing has been seen as the domain of the Medical Physics Department, involving extensive use of tissue-mimicking phantoms (TMPs) and other test devices. Over time, it has been recognized that sonographers have an essential role in the QA of ultrasound scanners. There are three levels of QA: level 1 (infection control and scanner damage), level 2 (basic scanner and transducer testing) and level 3 (further scanner and transducer testing). These tests are performed daily and weekly for level 1, daily for level 2 and monthly for level $3[18,19]$.

An audit should be performed on every professional practice aimed at taking corrective measures where errors are identified and improvement in the practice where errors are not identified. However, an empirical study shows that an audit of ultrasound practice has not been performed in some centres in Kano metropolis, and a literature review showed no documented published work in the study area. This may lead to an uncertainty about the reliability of diagnosis and patient care. The findings of the study will serve as a baseline for making recommendations to the relevant authorities or professional bodies to improve on regulations regarding ultrasound practices so as to enhance proper diagnosis and patient care. It will also serve as a guide for practitioners to improve on their technical skills and expertise. The study aims at evaluating the current status of ultrasound practice in Kano metropolis, Nigeria.

\section{Methods}

This study was a cross-sectional conducted among ultrasound practitioners in Kano metropolis, Nigeria, from December 2020 to January 2021. An ethical approval to conduct the study was obtained from the Human Research and Ethics Committee of the Ministry of Health, Kano State (MOH/Off/797/T.I/2117). An informed consent was obtained from all the respondents (Additional file 1). A structured questionnaire was used as an instrument for data collection (Additional file 2). The questionnaire was validated by experienced colleagues using content validity. The reliability of the measuring tool was tested using the test-retest method; the questionnaire was administered to a single group of people on two separate occasions at a 2-week interval. The relationship between the respondent scores from the two different administrations was estimated through statistical correlation, and the Cronbach alpha reliability coefficient was found to be 0.84. All ultrasound practitioners within the Kano metropolis were included and those practicing not within the study area were all excluded from the study. Seventy questionnaires were distributed to the respondents. A knowledge score of $50 \%$ and above was considered to be good and less than $50 \%$ as poor in this study. Descriptive statistics was employed to determine the distribution of all responses using SPSS version 21.0.

\section{Results}

Out of the $70(100 \%)$ administered questionnaires, 68 (97.14\%) were returned, and 64 (91.43\%) were properly filled.

Figure 1 shows that majority of the respondents were between the age range of $20-30$ years 31 (48.4\%), 


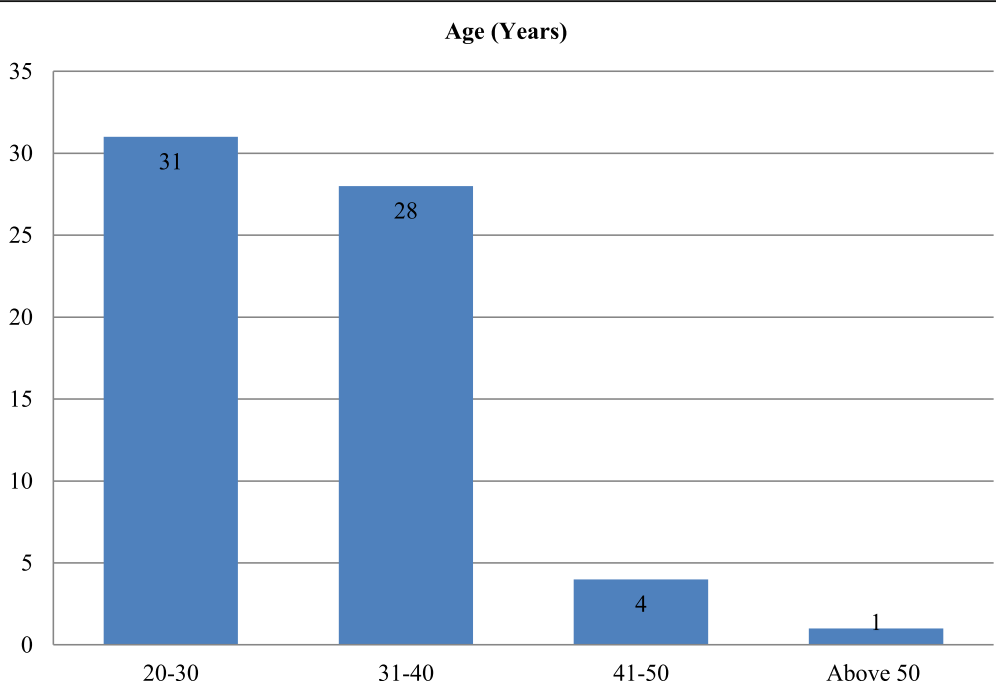

Fig. 1 Age distribution of the respondents

followed by 31-40 years, while those between the age range of 41-50 years were the least among the respondents followed by those above 50 years of age.

Figure 2 shows that out of 64 respondents, 56 (87.5\%) were male while $8(12.5 \%)$ were female.

Figure 3 shows that $50(78.1 \%)$ of the respondents were radiographers followed by radiology residence 8 (12.5\%), while radiologists, sonographers and nurses were found to be $2(3.12 \%)$ each respectively.

Figure 4 shows more than $85 \%$ (55) of the respondents had 1-5 years range of work experience followed by those with $11-15$ years and $6-10$ years range $8 \%$ and $6 \%$ respectively.

Figure 5 shows a higher proportion of the respondents was working in tertiary hospitals $26(40.6 \%)$ which is almost the same with those working in private hospitals 25 (39\%). Six and five of the respondents were found to be working in private diagnostic centres and state specialist hospital respectively.

Table 1 shows that $58(90.6 \%)$ participants knew the exact definition of ultrasound imaging while $6(9.4 \%)$ of the participants did not, $56(87.5 \%)$ believed it is the most suitable imaging technique for guiding biopsies and fine needle aspirations that are performed percutaneously, and also $49(76.6 \%)$ of the respondents knew ultrasonography is used to diagnose chromosomal abnormalities in vitro, while $15(23.4 \%)$ thought it is not possible. On the same vein, 54 (84.4) of the respondents said it provides information on foetal and placental blood flow using Doppler mode. However, 30 (47\%) of the respondents do not consider ultrasonography as the first-line imaging modality used for diagnosis of abdominal masses while 34 (53\%) did.

Table 2 shows that majority of the respondents 49 (76.6\%) knew that ultrasound technology can be used in

Gender

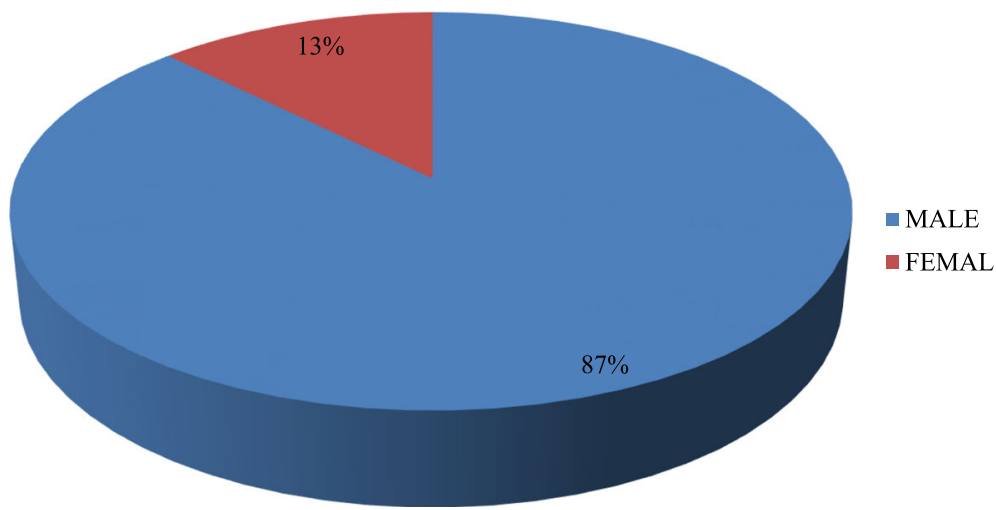

Fig. 2 Gender distribution of the respondents 


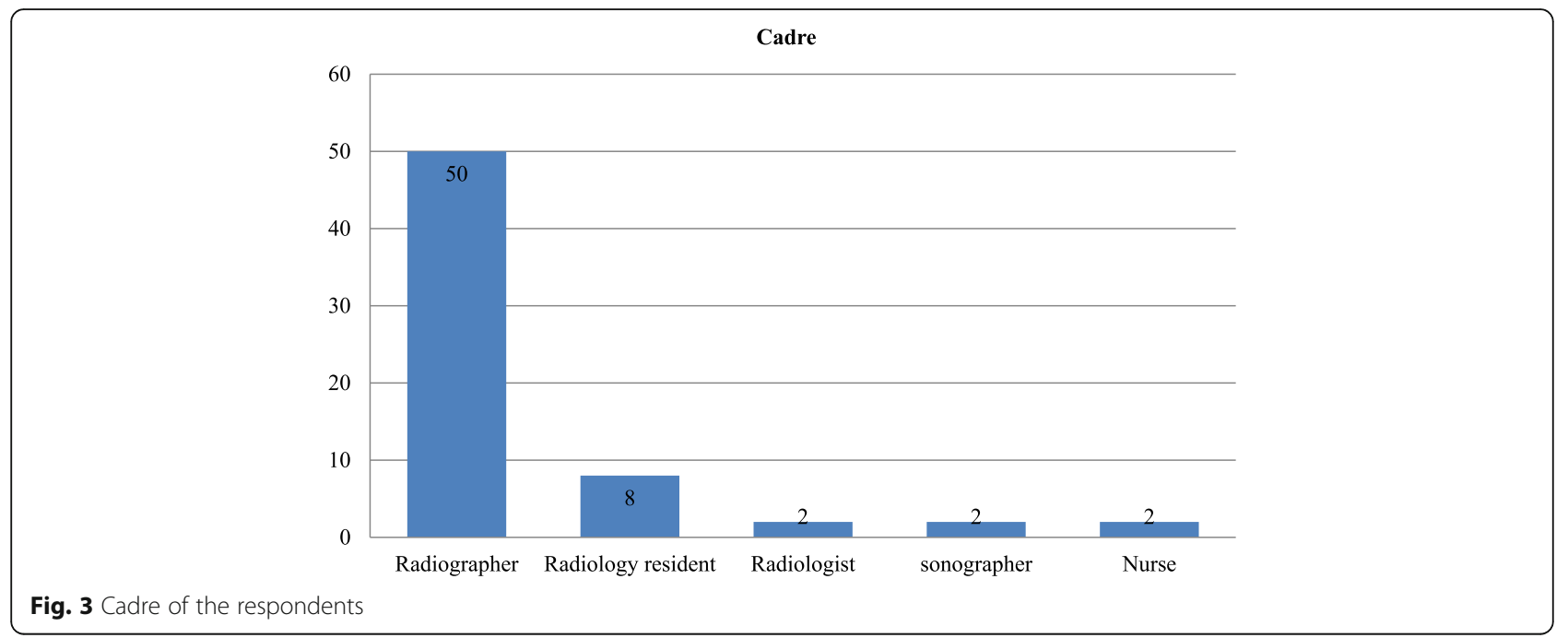

the therapy and image-guided drug delivery; however, 15 (23.4\%) thought it could not be used for that purpose; surprisingly, none of the respondents was aware with either of the following advanced ultrasound modality (3D, $4 \mathrm{D}$, echocardiography and sonoelastography) in their place of work. Majority of the respondents 38 (59.4\%) describe the resolution of their ultrasound machine as moderate, 9 (14.1\%) high, and 13 (20.3\%) low, while only $4(6.3 \%)$ of the respondents describe the resolution of their ultrasound machine as poor. Regarding participant qualification in the field of ultrasound, 54 (84.4) had degree as their highest qualification, only 11 (12.5\%) had an additional qualification in the field of ultrasound and 3 (4.7\%), 3 (4.7\%) and 2 (3.1\%) masters, PGD ultrasound

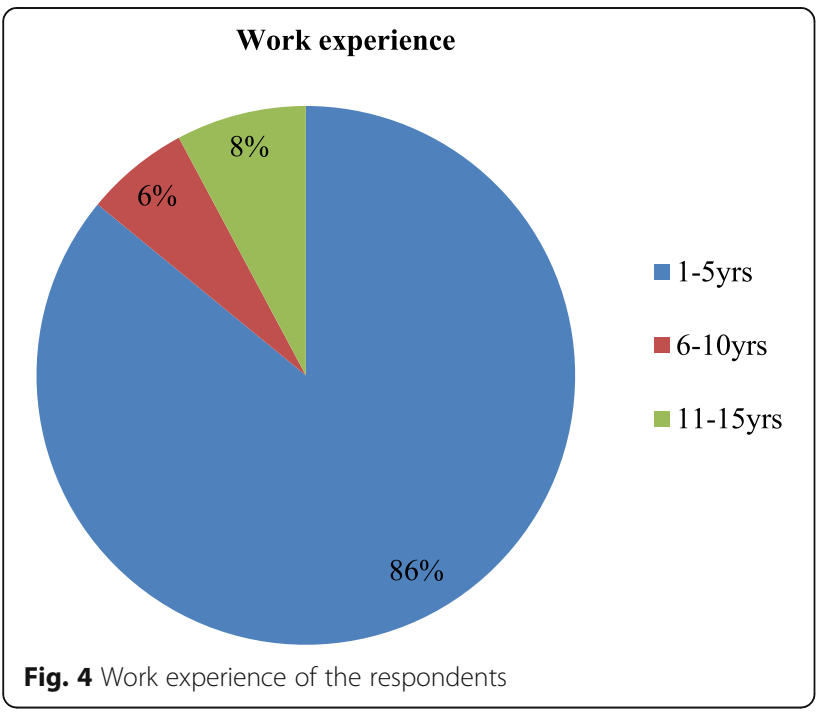

and Fellow West African College of Radiologist respectively.

Table 3 shows that $40(62.5 \%)$ of the respondents did not know the correct definition of quality assurance as regards ultrasound equipment; likewise, 41 (64\%) do not know who is responsible for carrying out quality assurance for ultrasound equipment. Sixty-one (95.3\%) of the respondents in this study do not perform checks on infection control as recommended. Majority of the respondents do not perform air reverberation pattern and electronic noise assessment 59 (92.2\%); also, only 31 (48.4\%) perform checks for brightness and grey scale bar display as required; meanwhile, 33 (51.6\%) did not.

\section{Discussion}

The findings of this study as shown in Fig. 1 show that majority of the respondents were within the age range of 20-30 years. This implies ultrasound practice in the study area may have a bright feature being majority of the personnel practicing are at their mid age. As indicated in Fig. 2, more than $87 \%$ of the respondents were male. The implication is that some patients may have a clear preference for a health care of specific gender due to their ethnic, religious or cultural background, because of previous experiences or in view of their age this may affect their right to have equal access to healthcare services as a citizen. As shown in Fig. 3, majority of the respondents in the current study were radiographers followed by radiology residence, while radiologist, sonographers and nurse were found to be the least among the respondents having contributed $3.12 \%$ each to the respondents respectively. The possible consequence is that radiographers are required to undergo more additional training in other to perform certain special 


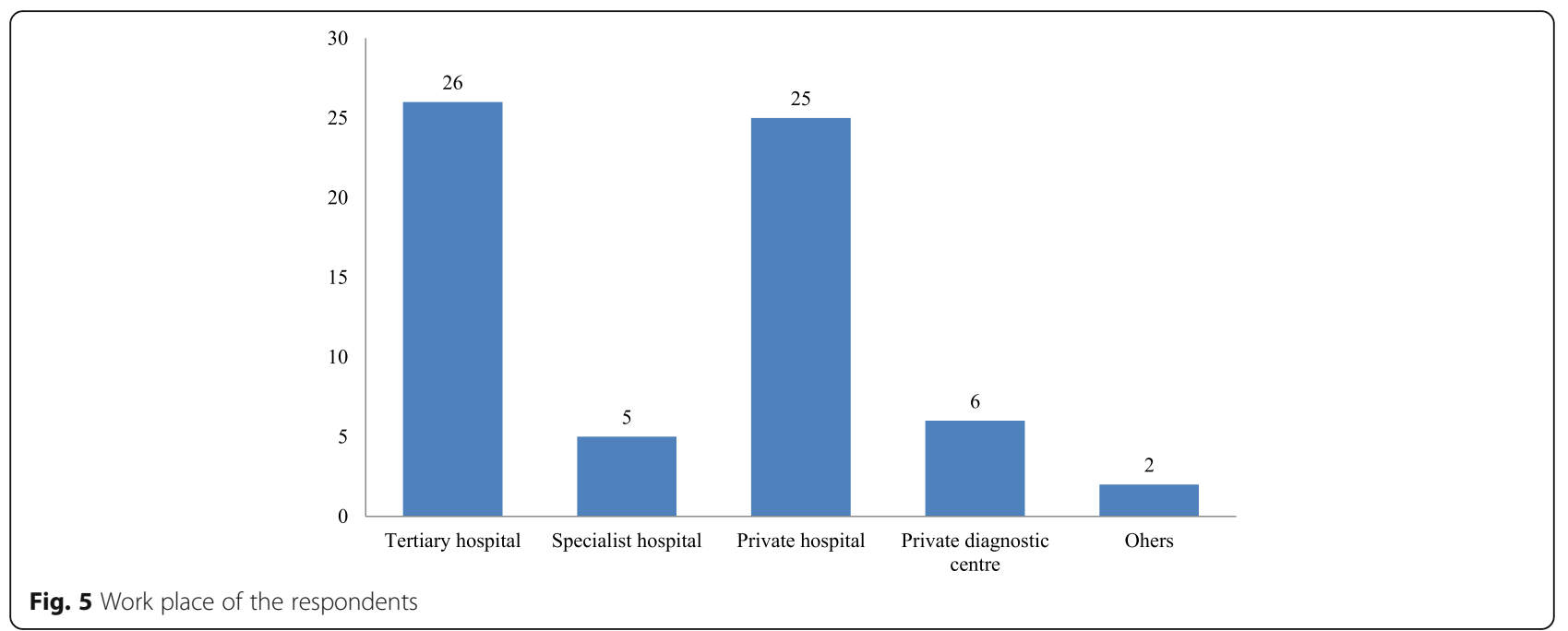

ultrasound procedures like small parts examination; their practice is also limited when it comes to invasive procedures such as biopsy. Figure 4 shows more than $85 \%$ of the respondents had 1-5 years range of working experience. This implies those with less working experience need to be supervised by more experienced personnel; the absence of which may lead to misdiagnosis by the less experience once. As indicated in Fig. 5, a higher proportion of the respondents were working in tertiary hospitals, which is almost the same with those working in private hospitals within the study area, and six and five of the respondents were found to be working with private diagnostic centres and state specialist hospital respectively.

The result of this study also as indicated in Table 1 shows that over $90 \%$ of the respondents knew the exact definition of ultrasound imaging while about $10 \%$ of the respondents did not. This is alarming as it will raise concern about the integrity of results issued by such personnel that did not know the definition of the modality they are operating. As indicated in Table 1, 87\% of the respondents believed ultrasound is the most suitable imaging technique for guiding biopsies and fine needle aspirations that are performed percutaneously. This finding implies that a patient that requires biopsy may be protected from exposure to ionizing radiation by computed tomography (CT) and cost of magnetic resonance imaging (MRI) biopsy procedure. Table 1 shows not less than $76 \%$ of the respondents knew ultrasonography is used to diagnose chromosomal abnormalities in utero, while about $24 \%$ thought it is not feasible. The concern is that diagnosis of chromosomal abnormalities that can be done in utero at around 11-14 weeks of gestation in order to decide on the fate of pregnancy may be delayed till birth. Congenital anomalies can contribute to long-term disabilities, which may have a significant effect on individuals, families, healthcare systems and societies [20]. On the same vein as indicated in Table 1, 84.4\% of the respondents knew that ultrasound can be employed to provide information on foetal and placental blood flow using Doppler; however, $15.6 \%$ consider it to be impossible. The possible implication is that the utilization of the umbilical artery Doppler flow to confirm or rule out certain intrauterine anomaly might be deprived by personnel with the latter opinion. Fortyseven percent of the respondents did not consider ultrasonography as the first-line imaging modality to be employed in the diagnosis of abdominal masses while

Table 1 Participant response on knowledge of ultrasound and its application in medical diagnosis

\begin{tabular}{|c|c|c|}
\hline \multirow[t]{2}{*}{ Questions } & \multicolumn{2}{|l|}{ Response } \\
\hline & $\begin{array}{l}\text { Positive } n \\
\text { (\%) }\end{array}$ & $\begin{array}{l}\text { Negative } n \\
(\%)\end{array}$ \\
\hline 6. Ultrasound imaging & $58(90.6)$ & $6(9.4)$ \\
\hline $\begin{array}{l}\text { 7. Is ultrasound the most applicable imaging technique for guiding biopsies and fine needle aspirations that are } \\
\text { performed percutaneously? }\end{array}$ & $56(87.5)$ & $8(12.5)$ \\
\hline 8. Can ultrasound be used to diagnose chromosomal abnormalities? & $49(76.6)$ & $15(23.6)$ \\
\hline 9. Ultrasound provides information on foetal and placental blood flow using? & $54(84.4)$ & $10(15.6)$ \\
\hline 10. Do you think ultrasound is the first line imaging modality in diagnosis of abdominal masses? & $34(53)$ & $30(47)$ \\
\hline
\end{tabular}


Table 2 Participant responses on their exposure to advanced ultrasound technology and standard of practice

\begin{tabular}{|c|c|c|}
\hline \multirow{2}{*}{$\begin{array}{l}\text { Questions } \\
11 . \text { Do you think ultrasound technology can be } \\
\text { used in the therapy and image guided drug } \\
\text { delivery? }\end{array}$} & \multicolumn{2}{|c|}{ Response N (\%) } \\
\hline & Yes 49 (76.6) & $\begin{array}{l}\text { No } 15 \\
(23.4)\end{array}$ \\
\hline $\begin{array}{l}\text { 12. Which of the following advanced modality } \\
\text { is available to you? }\end{array}$ & $\begin{array}{l}\text { None } 64 \\
(100)\end{array}$ & \\
\hline \multirow{4}{*}{$\begin{array}{l}\text { 13. How can you describe the resolution of the } \\
\text { ultrasound machine you are currently using? }\end{array}$} & Poor 4 (6.3) & \\
\hline & $\begin{array}{l}\text { Low } 13 \\
(20.3)\end{array}$ & \\
\hline & $\begin{array}{l}\text { Moderate } \\
38(59.4)\end{array}$ & \\
\hline & $\begin{array}{l}\text { High } 9 \\
(14.1)\end{array}$ & \\
\hline \multirow[t]{5}{*}{$\begin{array}{l}\text { 14. What is your qualification in the field of } \\
\text { ultrasound? }\end{array}$} & $\begin{array}{l}\text { Degree } 56 \\
(87.5)\end{array}$ & \\
\hline & PGD 3 (4.7) & \\
\hline & $\begin{array}{l}\text { Masters } 3 \\
(4.7)\end{array}$ & \\
\hline & $\mathrm{PhD}$ & \\
\hline & $\begin{array}{l}\text { FWCR } 2 \\
(3.1)\end{array}$ & \\
\hline \multirow[t]{3}{*}{$\begin{array}{l}\text { 15. Which regulatory body have you registered } \\
\text { with? }\end{array}$} & $\begin{array}{l}\text { RRBN } 52 \\
(81.3)\end{array}$ & \\
\hline & $\begin{array}{l}\text { MDCN } 10 \\
(15.6)\end{array}$ & \\
\hline & $\begin{array}{l}\text { NMCN } 2 \\
(3.1)\end{array}$ & \\
\hline
\end{tabular}

$53 \%$ did as shown in Table 1. The possible implication of this finding is that it may lead to underuse of the modality, which may leave referring physician with no option than to seek for the evaluation of abdominal masses using other imaging modalities such as conventional Xray, $\mathrm{CT}$ and MRI, and this might be invasive, costly and stressful to the patient. Brownlee et al. [21] considered a modality to be underutilized when it is not optimally deployed for its purposes perhaps due to inadequate knowledge and skills. Ultrasound is the first imaging modality of choice that can be employed in the diagnosis of abdominal masses [22, 23].
Table 2 shows more than $76 \%$ of the respondents knew that ultrasound technology can be used in the therapy and image-guided drug delivery; however, about $24 \%$ thought it could not be used for this purpose. This is probably because they only concentrate on general/ routine ultrasound scanning procedures and failed to partake in continue programme development (CPD). The implication is that the second opinion may limit the scope of ultrasound application in medicine. The findings of the current study found none of the respondents has either of the following advanced ultrasound modality: 3D, four dimensional (4D), echocardiography and sonoelastography in their place of work. This showed a lack of advanced ultrasound equipment in both government and private sector as indicated in Table 2. The possible explanation is that the contemporary twodimensional (2D) ultrasound is of such high quality that has hindered appreciation of 3D, 4D and sonoelastography ultrasound potentials towards improving the conventional $2 \mathrm{D}$ ultrasound. The possible problem is that patients might be subjected to unnecessary interventional procedures due to false-positive diagnosis on $2 \mathrm{D}$ ultrasound images as it lacks versatility in the characterization of some lesions or masses [24]. Findings of this study as indicated in Table 2 shows majority of the respondents described the resolution of their ultrasound machine as moderate, low and high 38 (59.4\%), $13(20.3 \%)$ and $9(14.1 \%)$ respectively while $4(6.3 \%)$ of the respondents described the resolution of their ultrasound machine as poor. The implication of using a machine with poor resolution is that it increases the chances of missing details which may lead to misinterpretation of the sonogram and subsequent false-positive or false-negative diagnosis. Table 2 shows almost $88 \%$ of the respondents had degree as their highest qualification and only 8 (12.5\%) had an additional qualification in the field of ultrasound; out of which three had Master's degree and Postgraduate Diploma (PGD) in ultrasound each, respectively, and two were Fellow West African College of Radiologist (FWACR). These findings suggest most of the respondents did not undergo further training on ultrasonography which is paramount for efficient service delivery in every medical practice. The WHO

Table 3 Participant responses on the practice of quality assurance on medical ultrasound equipment

\begin{tabular}{|c|c|c|}
\hline \multirow[t]{2}{*}{ Questions } & \multicolumn{2}{|l|}{ Response } \\
\hline & Positive n (\%) & Negative $\mathrm{n}(\%)$ \\
\hline 16. Quality assurance program & $24(37.5)$ & $40(62.5)$ \\
\hline 17. Who do you think is responsible for carrying out quality assurance for ultrasound equipment? & $23(36)$ & $41(64)$ \\
\hline 18. How often do you perform checks on infection control? & $3(4.7)$ & $61(95.3)$ \\
\hline 19. How often do you perform air reverberation pattern and electronic noise assessment? & $5(7.8)$ & $59(92.2)$ \\
\hline 20. How frequent do you check for brightness and grey scale bar display? & $31(48.4)$ & $33(51.6)$ \\
\hline
\end{tabular}


(1998) [3] recommends an advanced-level ultrasonography training of at least 3years (full time) postdegree and 3-9 months of training for trainees that had completed their training programme in radiology. Ultrasound is operator dependent and hence depends on the experience and expertise of the ultrasound examiner [4]. The concern here is ultrasound can be misleading and dangerous in the hands of untrained or poorly trained personnel. As indicated in Table 2, over $81 \%$ of the respondents were registered with the Radiographers Registration Board of Nigeria, while ten and two out of 64 respondents were registered with the Medical and Dental Council of Nigeria and Nursing and Midwifery Council of Nigeria respectively. This implies ultrasound practitioners in the study area were registered with a different regulatory body that is responsible for regulating the practice of its members. The implication is that each regulatory body may have its own way or requirement for certifying its members to practice ultrasonography or the body might not even consider regulating ultrasound practice by its members as part of its responsibility, thereby creating room for quackery practice which is a detriment to the patients.

The study found as noted in Table 3 more than 60\% of the respondents did not know the correct definition of quality assurance with regard to ultrasound equipment; likewise, $64 \%$ of the respondents do not know who is responsible for carrying out quality assurance practice on ultrasound equipment as shown in Table 3. These findings imply ultrasound equipment in the study area were most likely been operated without a routine quality assurance plan in place which may probably undermine the quality of images produced by the equipment and the subsequent inference derived from such images, thereby increasing the risk of inappropriate diagnosis. Routine QC ensures that the equipment is operating at optimal operational condition, thereby providing the required diagnostic information [25]. There is increasing evidence in the literature of the efficacy of formal QA programmes in identifying more subtle deterioration of ultrasound imaging performance [18]. It is also noted in Table 3 that more than $95 \%$ of the respondents in the current study did not perform checks on infection control as required. This finding implies patients might be subjected to a greater risk of contracting a nosocomial infection from ultrasound transducers and even examination couch; this is a threatening situation to the health condition of both the patients and personnel. Sartoretti et al. [26] reported that a contaminated ultrasound transducer contained more bacterial load than toilet seats or public bus poles. As indicated in Table 3, the current study found majority of the respondents did not perform air reverberation pattern and electronic noise assessment; also, only $48.4 \%$ of the respondents do perform checks for brightness and grey scale bar display as recommended; meanwhile, $51.6 \%$ did not observe such as shown in Table 3. This is not surprising considering the poor understanding of the quality assurance programme recorded by the respondents. The implications of these findings are subtle changes or malfunction of ultrasound equipment may not be picked up at its initial stage for appropriate action to be taken until it becomes apparent and devastated in which case little or nothing can be done to reverse the effects and damages recorded due to misdiagnosis that might have occurred unnoticed as a result of poor quality control practice.

\section{Conclusion}

The current study found good knowledge of ultrasound and its application in medical diagnosis among ultrasound practitioners. However, there was unavailability of advanced ultrasound equipment and the practitioners were seriously lagging behind in terms of continue personnel development (CPD). Furthermore, the practitioners demonstrated poor understanding and practice of the quality assurance programme on ultrasound equipment.

\section{Recommendations}

From the findings of this study, we make the following recommendations:

1. The management should encourage and support their personnel to undergo further training on ultrasound and its application.

2. Routine ultrasound equipment $\mathrm{QC}$ programme training should be organized for ultrasound practitioners.

3. Ultrasound practitioners should develop the habit of performing QC that is within their limit.

\section{Limitation}

A small sample size was used for the study.

Abbreviations

CASE: Consortium for the Accreditation of Sonographic Education; QA: Quality assurance; TMP: Tissue-mimicking phantom; PGD: Postgraduate Diploma; FWCR: Fellow West African College of Radiology; RRBN: Radiographers Registration Board of Nigeria; MDCN: Medical and Dental Council of Nigeria; NMCN: Nursing and Midwifery Council of Nigeria; CT: Computed tomography; MRI: Magnetic resonance imaging; CPD: Continue programme development

\section{Supplementary Information}

The online version contains supplementary material available at https://doi. org/10.1186/s43055-021-00509-x.

Additional file 1. Consent form for respondent.

Additional file 2. Questionnaire. 


\section{Acknowledgements}

Not applicable.

\section{Authors' contributions}

SM: Conceptualized the work and the major contributor in writing the manuscript. SGM: Design of the work and acquisition of the data. YA: Data editing and data analysis. DJZ: Result presentation and interpretation. SSL: Discussion. LG: Did the final revision of the manuscript. All authors read and approved the final manuscript.

\section{Funding}

This study was not funded.

\section{Availability of data and materials}

The datasets used and/or analysed during the current study are available from the corresponding author on reasonable request.

\section{Declarations}

\section{Ethics approval and consent to participate}

An ethical approval to conduct the study was obtained from the Human Research and Ethics Committee of the Ministry of Health, Kano State $(\mathrm{MOH} /$ Off/797/T.I/2117). A written informed consent was also obtained from each of the respondents before participating in the study.

\section{Consent for publication}

Written informed consent for publication was obtained from all the respondents, and they are reassured that all information will be kept confidential and will only be used for the purpose of this study (Additional file 1). A reference number is not applicable.

\section{Competing interests}

The authors declare that they have no competing interests.

\section{Author details}

${ }^{1}$ Department of Medical Radiography, Faculty of Allied Health Sciences, Bayero University, Kano, Nigeria. ${ }^{2}$ Radiology Department, Aminu Kano Teaching Hospital, Kano, Nigeria. ${ }^{3}$ Department of Medical Radiography, Federal University Lafia, Lafia, Nasaraw State, Nigeria. ${ }^{4}$ Department of Medical Radiography, Faculty of Allied Health Sciences, College of Medical Sciences, Ahmadu Bello University, Zaria, Kaduna State, Nigeria. ${ }^{5}$ Department of Medical Radiography, Faculty of Health Sciences, College of Medical Sciences, University of Maiduguri, Maiduguri, Borno State, Nigeria.

Received: 11 January 2021 Accepted: 6 May 2021

Published online: 26 August 2021

\section{References}

1. Dias T (2009) The role of ultrasound in obstetrics. Obstet Gynacol 31(2):7683

2. Chan V, Perlas A (2011) Basics of ultrasound imaging. In: Atlas of ultrasoundguided procedures in interventional pain management. Springer Science+ Business Media www.researchgate.net/publication/225262445. Accessed 8 Oct 2020

3. World Health Organisation (1998) Training in diagnostic ultrasound: essentials, principles and standards: report of a WHO study group. Geneva. Available at: whqlibdoc.who.inttrrs;WHOTRS875. Accessed 25 Nov 2020

4. Halton J, Kosack CS, Spijker S, Brant WE, Andronikou S (2018) Ultrasound manual for trained practitioners. Amsterdam: Medecins Sans Frontieres

5. Khati NJ, Gorodenker J, Hill MC (2011) Ultrasound-guided biopsies of the abdomen. Ultrasound Q 27(4):255-268. https://doi.org/10.1097/RUQ.0b013 e3182394101

6. The Royal College of Radiologist, The Society and College of Radiographer (2014) Standard for the provision of an ultrasound services. London. Available at: www.rcr.ac.uk. Accesse 25 Nov 2020

7. Society and College of Radiographers and British Medical Ultrasound Society (2019) Guidelines for professional ultrasound practice.

8. Thomson N (2009) The scope of practice in medical ultrasound. Published on Society of Radiographers. https://www.sor.org. Accessed 25 Nov 2020.

9. Gegor CL (1992) Obstetric ultrasound: who should perform sonograms? Birth 19(2):92-99. https://doi.org/10.1111/j.1523-536X.1992.tb00385.x
10. Rehani B, Brown I, Dandekar S, Sarkodi B, Mwango G, Rehani MM et al (2016) Radiology education in Africa: analysis of result from 13 African countries. JACR 14(2):247-252. https://doi.org/10.1016/j.jacr.2016.08.012

11. Idowu BM (2018) Postgraduate radiology education in Nigeria: looking backward and forward. SA J Radiol 22(1):1-7

12. Radiographers Registration, etc ACT. (CAP R1 LFN) (2005) Registration of radiographers regulations.

13. Leslie A, Lockyer H, Virjee JP (2000) Who should be performing routine abdominal ultrasound? A prospective double-blind study comparing the accuracy of radiologist and radiographer. Clin Radiol 55(8):606-609. https:// doi.org/10.1053/crad.2000.0491

14. Riley SJ, Groves CJ, Chandramohan M (2010) Musculoskeletal ultrasound: audit of sonographer reporting. Ultrasound 18(1):36-40. https://doi.org/1 0.1258/ult.2009.009011

15. Hofmann B, Vikestad KG (2013) Accuracy of upper abdominal examinations by sonographers in Norway. Radiography 19(3):186-189. https://doi.org/10.1 016/j.radi.2013.05.001

16. Rix A, Lederle W, Theek B, Lammers T, Moonen C, Schmitz G, Kiessling F (2018) Advanced ultrasound technologies for diagnosis and therapy. JNM 59(5):740-746. https://doi.org/10.2967/jnumed.117.200030

17. Kok T, van der Jagt EJ, Haagsma EB, Bijleveld CM, Jansen PL et al (1999) The value of doppler ultrasound in cirrhosis and portal hypertension. Scand J Gastroenterol 230:82-88

18. Dudley N (2014) Guidelines for the regular quality assurance testing of ultrasound scanners by sonographers. J Med Ultasound 22:8-14

19. Balbis S, Meloni T, Tofani S, Zenone F, Nucera D, Guiot C (2012) Criteria and scheduling of quality control of B-mode and Doppler ultrasonography equipment. JCU 40(3):167-173. https://doi.org/10.1002/jcu.21897

20. Sidi M (2020) The role of prenatal ultrasound in the detection of fetal anomalies: a systematic review. NJMIT 8(2):95-101

21. Brownlee S, Chalkidou K, Doust J, Elshaug AG, Glasziou P, Heath I.et al (2017) Evidence for overuse of medical services around the world. Right Care 1. www.thelancet.com. Accessed 27 Nov 2020.

22. Fowler KJ, Garcia EM, Kim DH, Cash BD, Chang KJ, Feig BW et al (2019) Palpable abdominal mass-suspected neuplasm. J Am Coll Radiol 16(116): 383-391

23. Caraiani C, Yi D, Petresc B, Dietrich C (2020) Indications for abdominal imaging: when and what to choose? J Ultrason 20:43-54

24. Yildiz MS, Goya C, Adin MD (2020) Contribution of sonoelastography to diagnosis in distinguishing benign and malignant breast masses. J Ultrasound Med 9999:1-9

25. Sidi M, Hussain UY, Ya'u A, Garba I (2020) Evaluation of the computed tomography number for water, field uniformity, image noise and contrast resolutions in Kano metropolis, Nigeria. NJBCS 17:21-25

26. Sartoretti T, Sartoretti E, Bucher C, Doert A, Binkert C, Hergan K et al (2017) Bacterial contamination of ultrasound probes in different radiological institutions before and after specific hygiene training: do we have a general hygienical problem? Eur Radiol 27(10):4181-4187

\section{Publisher's Note}

Springer Nature remains neutral with regard to jurisdictional claims in published maps and institutional affiliations.

\section{Submit your manuscript to a SpringerOpen ${ }^{\circ}$ journal and benefit from:}

- Convenient online submission

- Rigorous peer review

- Open access: articles freely available online

High visibility within the field

- Retaining the copyright to your article

Submit your next manuscript at $\boldsymbol{\nabla}$ springeropen.com 